\title{
Atendimento Educacional Especializado: Reflexóes Sobre a Demanda de Alunos Matriculados e a Oferta de Salas de Recursos Multifuncionais na Rede Municipal de Manaus-AM ${ }^{1}$ SpeCIAL EDUCATION SERVICE: ReFLECTIONS ON THE DEMAND FOR STUDENTS Registered and the OfFering of Multifunctional Resources Classrooms IN THE MUNICIPAL NETWORK OF MANAUS-AM
}

\author{
João Otacílio Libardoni dos SANTOS ${ }^{2}$ \\ Maria Almerinda de Souza MATOS ${ }^{3}$ \\ Geyse Pattrizzia Teixeira SADIM ${ }^{4}$ \\ João Rakson Angelim da SILVA ${ }^{5}$ \\ Marta Patricia FAIANCA ${ }^{6}$
}

\begin{abstract}
RESUMO: este estudo objetiva evidenciar e discutir os dados referentes às ofertas das Salas de Recursos Multifuncionais (SRM), como espaço de Atendimento Educacional Especializado (AEE), mapeados na Rede Municipal em Manaus, com intenção de entender como esses serviços estão sendo organizados em cumprimento aos dispositivos legais para sua implementação. Como pesquisa quantitativa, de caráter descritivo, discute os dados referentes às SRM. Inicialmente fez-se um levantamento documental por meio dos regulamentos de âmbito federal que regulamentam e caracterizam a política de inclusão escolar (Educação Inclusiva). Em seguida, foram coletados dados oficiais do Instituto Nacional de Estudos e Pesquisas Educacionais Anísio Teixeira (INEP) e da Secretaria Municipal de Educação (SEMED/Manaus) referente aos números de SRM e de alunos da Educação Especial matriculados em classes comuns, e em classes exclusivas, no Brasil e em Manaus (2009 - 2015). Levantou-se para discutir: 1) o número de alunos da Educação Especial matriculados em Classes Comuns do Ensino Regular por Divisáo Distrital Zonal (DDZ); e 2) o número de escolas municipais que possuem SRM, distribuídos por DDZ das áreas urbanas e rural. Os resultados revelaram que o quantitativo de SRM implementadas na rede municipal de ensino, nos últimos três anos (2014 a 2016), tem sido insuficiente para atender o aumento de matrículas do público-alvo da Educação Especial no ensino regular. Conforme a pesquisa, estima-se um déficit de 30 SRM para atender a demanda vigente.
\end{abstract}

PALAVRAS-CHAVE: Educação Especial. Atendimento Educacional Especializado. Atendimento em Sala de Recursos.

\begin{abstract}
The purpose of this study is to present and discuss data on the offerings of the Multifunctional Resources Classrooms (MRC), as a Special Education Service space, mapped in the Municipal Network in Manaus, in order to understand how these services are being organized in compliance with legal provisions for its implementation. As a quantitative research, of a descriptive nature, it discusses the data referring to MRC. Initially, a bibliographic survey was proposed in federal documents that regulate and characterize the school inclusion policy (Inclusive Education). Next, official data were collected from National Institute of Educational Studies and Research Anísio Teixeira (INEP) and the Municipal Department of Education (SEMED/Manaus) regarding MRC numbers and Special Education students enrolled in common classes and in exclusive classes in Brazil and
\end{abstract}

\footnotetext{
${ }^{1}$ http://dx.doi.org/10.1590/S1413-65382317000300007

${ }^{2}$ Docente do Programa de Pós-Graduaçáo em Educação da Universidade Federal do Amazonas - UFAM, Manaus, AM, Brasil. jlibardoni@yahoo.com.br

${ }^{3}$ Docente do Programa de Pós-Graduação em Educação da Universidade Federal do Amazonas - UFAM, Manaus, AM, Brasil. profalmerinda@hotmail.com

${ }_{4}^{4}$ Mestranda em Educação no Programa de Pós-Graduação em Educação da Universidade Federal do Amazonas - UFAM, Manaus, AM, Brasil. geyse_sadim@hotmail.com

${ }^{5}$ Mestrando em Educação no Programa de Pós-Graduação em Educação da Universidade Federal do Amazonas - UFAM, Manaus, AM, Brasil. jrangelim@gmail.com

${ }^{6}$ Mestranda em Educação no Programa de Pós-Graduação em Educação da Universidade Federal do Amazonas - UFAM, Manaus, AM, Brasil.mpfaianca@gmail.com
} 
Manaus (2009-2015). We argue to discuss: 1) the number of Special Education students enrolled in Common Classes of Regular Education by District Zonal Division (DZD); And 2) the number of municipal schools that have MRC, distributed by DZD of urban and rural areas. The results revealed that the number of MRCs implemented in the municipal education network in the last three years (2014 to 2016) has been insufficient to meet the increase in enrollments of the target population of special education in regular education. According to the survey, a deficit of $30 \mathrm{MRC}$ is estimated to meet current demand.

KEYWORDS: Special Education. Specialized Service. Attendance in Resources Classrooms.

\section{INTRODUÇÁO}

O sistema educacional tem passado por transformaçóes ao longo do tempo. A partir do Paradigma da Inclusão, baseado nos princípios dos Direitos Humanos, o reconhecimento e a valorização da diversidade são vistos como fatores de enriquecimento do processo de ensino aprendizagem.

Neste sentido, Noronha (2016) destaca que:

Os Direitos Humanos reforçam que a educação inclusiva é fundamental para sustentar e defender o exercício da dignidade humana e da cidadania. A necessidade de inclusão, por sua vez, não se restringe apenas aos educandos com algum tipo de deficiência [...]. Entende que a escola seja um espaço amplo que envolve todas as pessoas, pois a educação é um direito universal (p.38).

Seguindo nessa perspectiva, Oliveira (2015) coloca que a Educação Inclusiva propóe o acesso de todos às escolas de ensino regular, o que expressa não apenas um avanço conceitual, mas também significa uma mudança de paradigmas na educação.

A inclusão provoca, segundo Machado (2009), uma crise na escola, sobretudo quando defende o direito às pessoas com deficiência de frequentarem as salas de aula comuns, delatando o modelo de Educação Especial vigente que substitui o ensino regular e mantém soluçóes paliativas e excludentes para as questóes relativas a problemas de aprendizagem.

O Brasil, para se adequar à essas modificaçōes, vem definindo políticas públicas e criando instrumentos legais que garantem tais direitos. Um marco para a democratização do país, a Constituição Federal de 1988 (BRASIL, 1988) define o direito de todos à educação. No seu art. 206, inciso I, estabelece a "[...] igualdade de condiçôes de acesso e permanência na escola", como um dos princípios para o ensino e, garante, no art. 208, "[...] a oferta do atendimento educacional especializado, preferencialmente na rede regular de ensino" (BRASIL, 1988).

Fávero, Pantoja e Mantoan (2007, p. 26) ressaltam que “[...] apenas esses dispositivos legais bastariam para que ninguém negasse a qualquer pessoa com deficiência o acesso à mesma sala de aula de crianças ou adolescentes sem deficiência". Quanto ao "preferencialmente" constante na Constituição, Art. 208, inciso III, as autoras colocam que a Constituição admite que o Atendimento Educacional Especializado (AEE) seja também oferecido fora da rede regular de ensino, em outros estabelecimentos, já que seria um complemento e não um substitutivo à escolarização ministrada na rede regular para todos os alunos. Trata-se do atendimento que é necessariamente diferente do ensino escolar e que é indicado para melhor suprir as carências e atender as especificidades do alunado, e que inclui instrumentos necessários à elimina- 
ção de barreiras que as pessoas com deficiência têm para relacionar-se com o meio ambiente (FÁVERO; PANTOJA; MANTOAN, 2007).

Seguindo essa ótica, a Educação Especial integra a proposta pedagógica da escola regular, promovendo o AEE. Em conformidade com a Lei no 9.394/96 (BRASIL, 1996), Lei de Diretrizes e Bases da Educação Nacional (LDBEN), a Educação Especial é a modalidade de educação escolar oferecida preferencialmente na rede regular de ensino, para alunos com deficiência, transtornos globais do desenvolvimento e altas habilidades/superdotação, denominados como público-alvo da Educação Especial. Sobre esse mesmo assunto, no título III, art. 4º acrescentou o termo "gratuito" ao se referir ao AEE e, além disso, trocou o termo "portadores de deficiência" por "educandos com necessidades educacionais especiais" (BRASIL, 1996).

Porém, é a partir da Política Nacional de Educação Especial na Perspectiva da Educação Inclusiva de 2008 (BRASIL, 2008), que as discussões acerca da Educação Inclusiva no Brasil foram intensificadas. Com o objetivo de promover a inclusão escolar, prevê também a obrigatoriedade e gratuidade da oferta do AEE (BRASIL, 2008).

Assegurados em documentos normativos (BRASIL, 1988; BRASIL, 1996; BRASIL, 2009; BRASIL, 2011), o AEE que ocorre nas Salas de Recursos Multifuncionais (SRM) tem como função complementar ou suplementar a formação do aluno por meio da disponibilização de serviços, recursos de acessibilidade e estratégias que eliminem as barreiras para sua plena participação na sociedade e desenvolvimento de sua aprendizagem.

A Resolução CNE/CEB no 4/2009 (BRASIL, 2009), a qual institui diretrizes operacionais o AEE na Educação Básica, reafirma no artigo $3^{\circ}$ que a Educação Especial se realiza em todos os níveis, etapas e modalidades de ensino, tendo o AEE como parte integrante do processo educacional.

Desta forma, o Decreto no 7.611/2011 (BRASIL, 2011) define no parágrafo 3o, as SRM como ambientes dotados de equipamentos, mobiliários e materiais didáticos e pedagógicos para a oferta do AEE. Segundo o mesmo, o AEE compreende um conjunto de atividades, recursos de acessibilidade e pedagógicos, organizados institucional e continuamente, prestados de forma complementar à formação de estudantes com deficiência e transtornos globais do desenvolvimento; e suplementar à formação de estudantes com altas habilidades/superdotação (BRASIL, 2011).

Alves (2006) vai além, define o termo Salas de Recursos Multifuncionais (SRM) da seguinte forma:

A denominaçáo [...] se refere ao entendimento de que esse espaço pode ser utilizado para o atendimento das diversas necessidades educacionais especiais e para desenvolvimento das diferentes complementaçóes ou suplementaçóes curriculares. Uma mesma sala de recursos pode atender alunos com deficiência, autismo, hiperatividade ou outras necessidades educacionais especiais. Portanto, essa sala de recursos é multifuncional em virtude de a sua constituição ser flexível para promover os diversos tipos de acessibilidade ao currículo, de acordo com as necessidades de cada contexto educacional (p.14).

Desta forma, esclarece que a proposta de Educação Inclusiva, através do AEE realizado nas SRM, seja capaz de assegurar as necessidades específicas dos alunos. 
Neste sentido, a Lei no 13.146/2015 (BRASIL, 2015) que instituiu a Lei Brasileira de Inclusão da Pessoa com Deficiência (Estatuto da Pessoa com Deficiência), conhecida como LBI, em seu Art. $1^{\circ}$ assegura e promove, em condiçóes de igualdade, o exercício dos direitos e das liberdades fundamentais por pessoa com deficiência, visando à sua inclusão social e cidadania. Esta lei incumbe ao poder público, no Art. 28, a responsabilidade de assegurar, criar, desenvolver, implementar, incentivar, acompanhar e avaliar: o sistema educacional inclusivo em todos os níveis; aprimorar os sistemas educacionais; e institucionalizar, por meio do projeto pedagógico, o AEE, assim como os demais serviços e adaptaçóes razoáveis, que atendam as características dos estudantes com deficiência e garantam o seu pleno acesso ao currículo em condiçóes de igualdade, para conquistar o pleno exercício de sua cidadania (BRASIL, 2015).

No entanto, apesar de todo o esforço legal, reafirmado pela Política de Educação Inclusiva de 2008 (BRASIL, 2008), a qual garante a obrigatoriedade da matrícula dos alunos do público-alvo da Educação Especial no ensino regular e ainda dá apoio à garantia da oferta do AEE, acreditamos que na prática isto não é cumprido. Assim, o que se tem discutido é a relação entre ao aumento de alunos matriculados nos últimos anos e a criação de novas SRM para suprir estas demandas.

Sendo assim, este estudo tem como objetivo evidenciar e discutir os dados referentes às ofertas das SRM, como espaço de oferta do AEE, mapeados na Rede de Ensino Municipal de Manaus, com intenção de entender como esses serviços estão sendo organizados em cumprimento aos dispositivos legais para sua implementação. Levanta-se a hipótese de que o número de SRM da rede municipal de ensino, nos últimos três anos, tem sido insuficiente para atender o aumento de matrículas de alunos do público-alvo da Educação Especial no ensino regular.

\section{Método}

Essa pesquisa se caracteriza como quantitativa, de caráter descritivo, o qual Gil (2002, p.42) caracteriza como "a descrição das características de determinada população ou fenômeno", na ocasiāo discute-se os dados numéricos referentes às SRM.

No primeiro momento, foi realizado um levantamento documental por meio dos regulamentos de âmbito federal que determinam e caracterizam a política de inclusão escolar no Brasil (BRASIL, 1988; BRASIL, 1996; BRASIL, 2008; BRASIL, 2009; BRASIL, 2011; BRASIL, 2015).

Em segundo momento, com o objetivo de mapear os indicadores de matrícula, foi feito um levantamento quantitativo de alunos com necessidades especiais, no Brasil e em Manaus, matriculados em classes comuns, e em classes exclusivas, com base no Censo Educacional - Sinopse Estatística da Educação Básica, realizado pelo Instituto Nacional de Estudos e Pesquisas Educacionais Anísio Teixeira (INEP) (BRASIL, 2016) e, da base de dados da Secretaria Municipal de Educação (SEMED/Manaus).

No terceiro momento, foi solicitado, formalmente, à SEMED, via ofício, por meio do Departamento de Gestão Escolar: o número de SRM implementadas nos últimos três anos (2014 - 2016) na rede municipal de ensino; e o número de matrículas de alunos inclusos no sistema no mesmo período. Obteve-se a primeira solicitação quanto às SRM, e somente os dados do ano 
de 2016, referente às matrículas. Além dessas informaçóes, foi possível obter os dados a seguir do sistema municipal de ensino no período de 2015 e 2016: 1) número de alunos com Deficiência, Transtornos Globais do Desenvolvimento e Altas Habilidades/Superdotação matriculados em Classes Comuns do Ensino Regular por Divisão Distrital Zonal (DDZ); e 2) o número de escolas municipais que possuem SRM, distribuídos por DDZ das áreas urbanas e rural.

Os dados obtidos mediante levantamento foram agrupados em tabelas e gráficos, possibilitando sua análise estatística, sendo organizados da seguinte forma:

1. Conforme as sinopses supracitadas pelo INEP (BRASIL, 2016), os dados da Tabela 1, discorrem sobre o contingente de alunos, público-alvo da Educação Especial, matriculados na Educação Básica, em classes comuns e em classes exclusivas no período de 2009 e 2015 , em escolas públicas e privadas, dispostos da esfera federal para a municipal, polarizando os anos de 2009, como início da implantação da Política Nacional de Educação Especial na Perspectiva da Educação Inclusiva (BRASIL, 2008); e de 2015 por conter os dados mais atualizados no Inep;

2. Os dados da Tabela 2, oriundos do Departamento de Gestão Escolar/SEMED/Manaus, discorrem sobre o número de alunos incluídos em classes comuns da rede municipal de ensino, e os números de escolas com alunos incluídos, de Salas de Recursos (SR), e de SRM, ocorridos no período de 2014 a 2016. Na coluna "Alunos incluídos", os dados referentes aos anos de 2014 e 2015, foram obtidos do INEP/Censo Escolar (BRASIL, 2016), para os quais se considerou escolas das áreas urbana e rural com atendimento na rede pública municipal;

3. Na Tabela 3, agrupamos os dados dos Gráficos 1 e 2 com o objetivo de relacionar a capacidade atual de AEE com o número ideal de SRM que suprisse a necessidade do público-alvo da Educação Especial.

4. No Gráfico 1, demonstramos a oscilação entre o número de escolas (com alunos incluídos) e o número de SRM, ocorrido em 2016, distribuídas por DDZ na rede municipal de ensino;

5. No Gráfico 2, relacionamos o número total de alunos matriculados no ensino regular com o número de alunos incluídos na rede municipal de ensino, distribuídos por DDZ. Esses dados dos dois gráficos foram fornecidos pelo Departamento de Gestão Escolar/SEMED/Manaus.

\section{Resultados E Discussóes}

O levantamento feito neste estudo, com base nos dados do Censo da Educação Básica (BRASIL, 2016) revelou que, no Brasil no período entre 2009 e 2015, as matrículas de alunos do público-alvo da Educação Especial na Educação Básica, em escolas públicas e privadas, cresceram 45,5\%, passando de 639.718, em 2009, para 930.683 matrículas, em 2015 (Tabela 1) ${ }^{7}$.

\footnotetext{
${ }^{7}$ Segundo o INEP, o total da Educaçâo Especial inclui matrículas de alunos com algum tipo de deficiência, transtorno global do desenvolvimento ou altas habilidades/superdotação em Classes Exclusivas (Escolas Exclusivamente Especializadas) e em Classes Comuns de Ensino Regular e/ou EJA.
} 
Tabela 1 - Matrícula de Alunos com Deficiência, Transtornos Globais do Desenvolvimento e Altas Habilidades/Superdotação por tipo de Atendimento.

\begin{tabular}{ccccccccc}
\hline \multicolumn{3}{c}{ Brasil } & \multicolumn{5}{c}{ Manaus/AM } \\
\hline Matríc. & $\begin{array}{c}\mathbf{2 0 0 9} \\
\mathbf{( \% )}\end{array}$ & $\begin{array}{c}\mathbf{2 0 0 9} \\
\text { (absoluto) }\end{array}$ & $\begin{array}{c}\mathbf{2 0 1 5} \\
\mathbf{( \% )}\end{array}$ & $\begin{array}{c}\mathbf{2 0 1 5} \\
\text { (absoluto) }\end{array}$ & $\begin{array}{c}\mathbf{2 0 0 9} \\
\mathbf{( \% )}\end{array}$ & $\begin{array}{c}\mathbf{2 0 0 9} \\
\text { (absoluto) }\end{array}$ & $\begin{array}{c}\mathbf{2 0 1 5} \\
(\mathbf{\%})\end{array}$ & $\begin{array}{c}\mathbf{2 0 1 5} \\
\text { (absoluto) }\end{array}$ \\
\hline $\begin{array}{c}\text { Classes } \\
\text { comuns }\end{array}$ & 60,50 & 387.031 & 80,70 & 750.983 & 34,20 & 980 & 75,70 & 4.085 \\
$\begin{array}{c}\text { Classes } \\
\text { exclusivas }\end{array}$ & 39,50 & 252.687 & 19,30 & 179.700 & 65,90 & 1.889 & 24,30 & 1.315 \\
TOTAL & $\mathbf{1 0 0}$ & $\mathbf{6 3 9 . 7 1 8}$ & $\mathbf{1 0 0}$ & $\mathbf{9 3 0 . 6 8 3}$ & $\mathbf{1 0 0}$ & $\mathbf{2 . 8 6 9}$ & $\mathbf{1 0 0}$ & $\mathbf{5 . 4 0 0}$ \\
\hline
\end{tabular}

Fonte: Inep/DEED/Censo Escolar. Elaboração própria.

No entanto, observa-se que este crescimento foi maior no município de Manaus, onde no mesmo período, o crescimento de matrícula, em escolas públicas e privadas para essa população na Educação Básica, foi de 88,22\%; passando de 2.869, em 2009, para 5.400 matrículas, em 2015 (Tabela 1). Foram considerados, para essa análise, os referenciais do INEP (BRASIL, 2016) para os totais referentes às áreas urbana e rural das esferas federal, estadual e municipal, de escolas públicas e privadas.

Outro aspecto importante a ser destacado foi a relação inversa entre o aumento das matrículas em classes comuns ${ }^{8}$ e a diminuição em classes exclusivas ${ }^{9}$. Ao nível nacional, as matrículas vêm crescendo a cada ano em classes comuns, aumentando de 60,5\% para 80,7\% entre 2009 e 2015, respectivamente, e diminuindo nessa mesma intensidade nas classes exclusivas, passando de 39,5\% para 19,3\% no mesmo período.

Nessa mesma ótica, em Manaus, revelou-se que as matrículas seguem a mesma tendência de crescimento, aumentando em classes comuns, de 34,2\% para 75,7\% entre 2009 e 2015, respectivamente, e diminuindo nessa mesma intensidade nas classes exclusivas, passando de $65,9 \%$ para $24,3 \%$ no mesmo período.

Essas desproporcionalidades foram decorrentes da Política Nacional de Educação Especial na Perspectiva da Educação Inclusiva (BRASIL, 2008), a qual tem como objetivo:

[...] o acesso, a participação e a aprendizagem dos alunos com deficiência, transtornos globais do desenvolvimento e altas habilidades/superdotação nas escolas regulares, orientando os sistemas de ensino para promover respostas às necessidades educacionais especiais, garantindo: a transversalidade da educação especial desde a educação infantil até a educação superior; o Atendimento Educacional Especializado (AEE); a continuidade da escolarização nos níveis mais elevados do ensino; a formaçáo de professores para o AEE e demais profissionais da educação para a inclusão escolar; a participação da família e da comunidade; a acessibilidade urbanística, arquitetônica, nos mobiliários e equipamentos, nos transportes, na comunicação e informação; e a articulação intersetorial na implementação das políticas públicas (BRASIL, 2008, p.14).

\footnotetext{
${ }^{8}$ Segundo o INEP, a Educação Especial em Classes Comuns inclui matrículas de alunos com algum tipo de deficiência, transtorno global do desenvolvimento ou altas habilidades/superdotação de Ensino Regular e na EJA.

9 Segundo o INEP, a Educação Especial em Classes Exclusivas inclui matrículas de alunos com algum tipo de deficiência, transtorno global do desenvolvimento ou altas habilidades/superdotação em Escolas Exclusivamente Especializadas e/ou em Classes Especiais do Ensino Regular e/ou Educação de Jovens e Adultos (EJA).
} 
Outro ponto importante a ser destacado é o Plano Nacional de Educação (PNE), aprovado pela Lei no 13.005/2014 (BRASIL, 2014), o qual enfatiza na Meta 4 que o país deve universalizar até 2024, para a população de 4 a 17 anos, público da Educação Especial, o acesso à Educação Básica e ao AEE, com a garantia de sistema educacional inclusivo, de SRM, classes, escolas ou serviços especializados, públicos ou conveniados. Inicia-se uma trajetória que historicamente foi pautada nos princípios da segregação, que vem migrando homeopaticamente em direção ao processo de integração com uma perspectiva futurista de materializar uma política de Educação Inclusiva.

Este avanço significativo das matrículas de alunos incluídos demonstra a necessidade urgente de providências quanto à inclusão das crianças com deficiência nas escolas regulares e, principalmente, de preparar estas escolas, pedagogicamente, espacial e organizacionalmente, para inclusão real das crianças (KASPER et al., 2008). Sendo assim, apenas garantir o acesso ao ensino regular não é suficiente para estabelecer a inclusão, principalmente devido às fragilidades de infraestrutura e formação pedagógica encontrada nas escolas.

Neste sentido, o Programa de Implantação de Salas de Recursos Multifuncionais, instituído pelo MEC/SEESP por meio da Portaria Ministerial no 13/2007 foi estabelecido com o intuito de destinar apoio técnico e financeiro aos sistemas de ensino para garantir o acesso ao ensino regular e a oferta do AEE aos alunos do público-alvo da Educação Especial (BRASIL, 2007).

Seguindo em conformidade com a Política de 2008 (BRASIL, 2008), o Programa objetiva, entre outras coisas, assegurar o pleno acesso dos alunos do público-alvo da Educação Especial no ensino regular em igualdade de condiçóes com os demais alunos e disponibilizar recursos pedagógicos e de acessibilidade às escolas regulares da rede pública de ensino, orientando e refirmando, assim, a implantação das SRM (BRASIL, 2007). Sendo assim, espera-se que, com o aumento do número de matrículas no ensino regular, o AEE, por intermédio das SRM, também acompanhe está trajetória e se crie condiçóes suficientes para atender as crianças do público-alvo da Educação Especial.

Ao confrontar estas informaçóes com os dados do município de Manaus (Tabela 2), constatou-se, nos últimos 3 anos, que apesar do aumento do número de matrículas na Educação Especial no ensino regular da rede municipal (passando de 1.900, em 2014, para 3.024 alunos, em 2016, representando um aumento de 59,16\% de alunos, não houve um aumento significativo do número de SRM. É possível notar que o quantitativo de SRM oscilou gradativamente entre os anos de 2014 e 2015, aumentando de 42 para 50 salas; reduzindo em 2016 para 46 salas. No entanto, curiosamente, neste período, o que aumentou foi a criação de Salas de Recursos (SR) (83,40\%), passando de 17 para 31 salas, as quais criadas com recursos do município (Tabela 2). A SR é firmada no paradigma da integração e não atende todos os públicos da Educação Especial, diferente da SRM, a qual é instituída a partir do princípio da inclusão. 
Tabela 2 - Número de Matrículas Números de Escolas, Salas de Recursos, Salas de Recursos Multifuncionais na Educação Especial em Classes Comuns (Ensino Regular e/ou EJA) Manaus (2014-2016).

\begin{tabular}{cccc}
\hline Ano & $\begin{array}{c}\text { Sala de Recursos } \\
\text { (SR) }\end{array}$ & $\begin{array}{c}\text { Sala de Recursos } \\
\text { Multifuncionais (SRM) }\end{array}$ & $\begin{array}{c}\text { Alunos } \\
\text { incluídos }\end{array}$ \\
\hline 2014 & 17 & 42 & $1.900\left(^{*}\right)$ \\
2015 & 24 & 50 & $2.351\left(^{*}\right)$ \\
2016 & 31 & 46 & 3.024 \\
\hline
\end{tabular}

Fonte: Inep/DEED/Censo Escolar. Elaboração própria

Legenda: Foram consideradas somente escolas localizadas nas áreas urbana e rural da rede pública municipal EJA - Educação de Jovens e Adultos

No que se refere às SR, estas atendem somente alunos com Deficiência Mental/ Intelectual e também os que apresentam transtornos funcionais específicos (TDH, Hiperatividade e Distúrbios de Aprendizagem). Ainda, as escolas onde estas salas estão implantadas é quem deve prover os materiais necessários, com recursos da rede municipal. Assim, geralmente, elas se resumem em materiais pedagógicos que, em algumas escolas, são confeccionados pelas próprias professoras dessas salas ou comprados pela própria escola. Em contrapartida, as SRM recebem muitos materiais, inclusive computadores e mobiliário adaptado, subsidiados pelo governo federal (BERTUOL, 2010).

Apesar de constatar certa estagnação na implantação de novas SRM, nos últimos anos em Manaus, tem-se observado um esforço estratégico do setor público municipal em atender as diretrizes previstas em lei quanto à localização e distribuição das SRM em todas as DDZ, no sentido de facilitar o acesso desse público às escolas (Gráfico 1). 


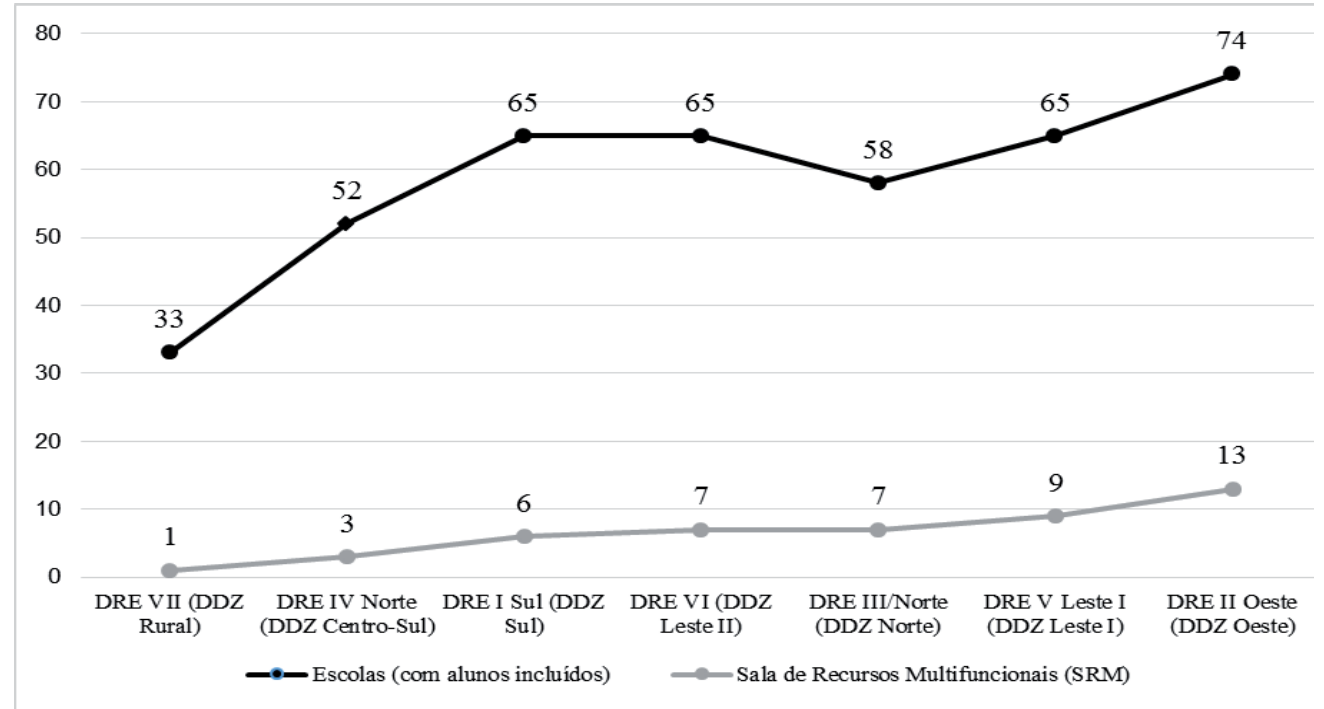

Gráfico 1 - Número de Escolas Municipais com alunos incluídos em classes comuns do Ensino Regular e Sala de Recursos Multifuncionais por Divisão Distrital Zonal (DDZ) SEMED/ MANAUS/2016.

No entanto, o que parece é que mesmo tendo esta preocupação na distribuição e organização, o número de SRM não obedece um critério claro de proporçóes (Gráfico 2). Nota-se que a relaçáo entre número de alunos alunos incluídos matriculados na rede municipal e SRM por DDZ varia (Gráficos 1 e 2), onde a DDZ Rural tem 1 SRM para atender 80 alunos incluídos e, na DDZ Oeste, tem 13 SRM para atender 599 alunos incluídos. Se somarmos os dados referentes as DDZ Leste I e II, obteremos 16 SRM para atender 954 alunos incluídos. Apesar das DDZs Leste I e II terem 28\% a mais alunos incluídos do que a DDZ Oeste, o mesmo não ocorreu em proporcionalidade no aumento das SRM. Esta mesma disparidade entre o número de escolas com alunos incluídos e o número de SRM pode ser visto nas demais DDZs (Gráficos 1 e 2). 


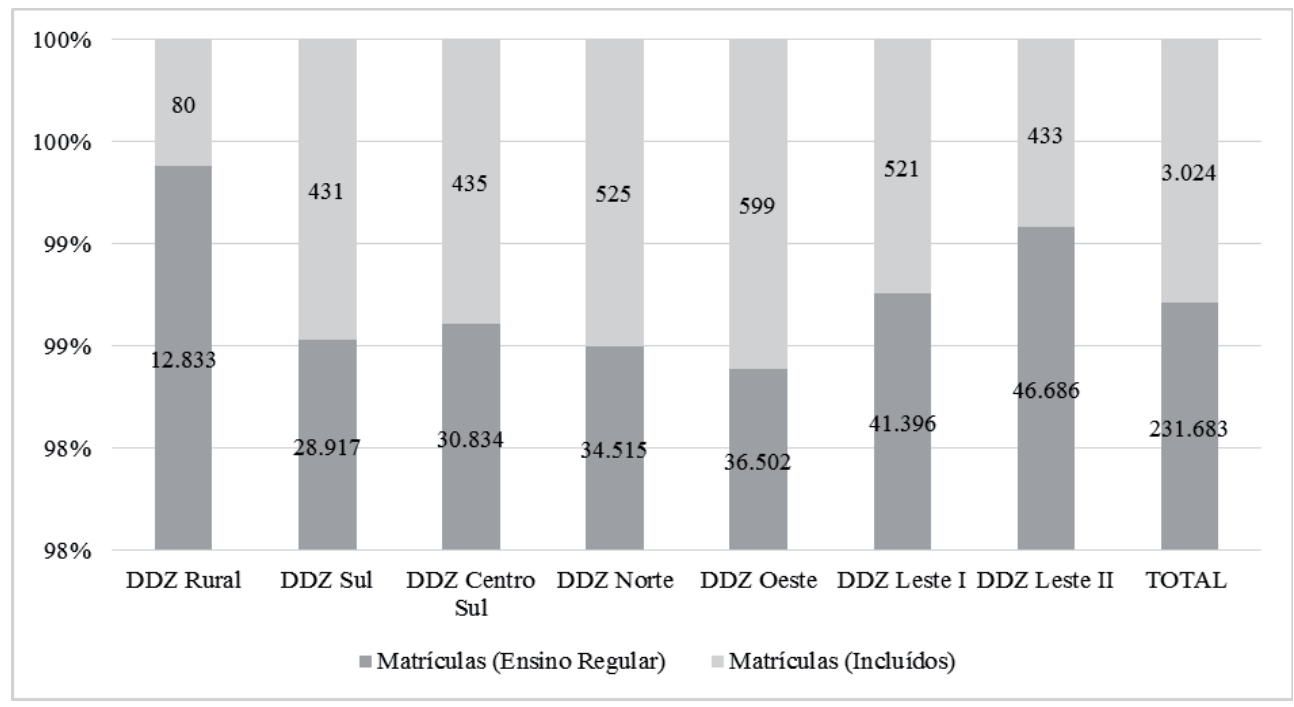

Gráfico 2 - Número de alunos matriculados no ensino regular e alunos incluídos por divisão distrital zonal (DDZ) SEMED/MANAUS/2016.

Outro ponto a se discutir é a organização do atendimento destes alunos de acodo com a disponibilidades das SRM. O atendimento ocorre, em média, por grupos de 15 a 20 alunos da própria escola e de escolas próximas da região, obedecendo a um cronograma de atendimento, no qual os alunos matriculados frequentam quatro horas-aulas, duas vezes por semana, em dias alternados, com duração de duas horas para cada atendimento (duas horas/ aulas). Este atendimento ocorre em período contrário ao que este está matriculado e frequentando a classe comum, computando uma carga horária, em cada SRM, de 20 horas/aulas semanais, sendo 16 horas/aula para efetivo trabalho pedagógico e 4 (quatro) horas-atividade do professor, em concordância com a legislação vigente. Em cada encontro, é atendido um grupo de no máximo cinco alunos, com duração de duas horas, programado duas vezes por semana. Há também uma flexibilizaçáo prevista no cronograma voltada para o atendimento individualizado ou em grupos menores, conforme necessidade e potencialidade de cada aluno.

A partir dessas informaçóes, e considerando atendimento em grupo, supomos calcular que a capacidade máxima de atendimento de cada SRM por turno seria de dois grupos compostos por cinco alunos cada, frequentando duas vezes por semana, somaria dez alunos por dia, o que suportaria atender por semana quatro grupos diferentes, cada um com cinco alunos, que totalizaria vinte alunos por semana. Considerando dois turnos, esses números dobrariam: quatro grupos com cinco pessoas, totalizando vinte alunos por dia, distribuídos em quatro horários diferentes com duração de duas horas cada, frequentando duas vezes por semana, totalizaria quarenta alunos por semana. Esses números oscilam em função da flexibilização centrada na necessidade de cada aluno; e das características pesentes no AEE, que considera a potencialização da capacidade desse aluno. Sendo assim, com base nessa reflexão, é possível afirmar que cada SRM suportaria atender, em sua capacidade máxima diurna, 40 alunos por semana. 
De acordo com os resultados desta pesquisa, percebe-se que o número de SRM disponível na rede municipal de ensino, ainda é insuficiente para atender a demanda existente (Tabela 3). Os dados revelaram que para atender tal demanda, seria necessário a existência de 76 SRM no município de Manaus (Tabela 3). No entanto, a rede municipal tem disponível o montante de 46 SRM para promover o AEE, o que demonstra que, apesar do esforço e empenho para atender esse público, existe um déficit de $40 \%$, ou seja, para suprir a demanda atual seria necessária a implantação de mais 30 SRM. Implica dizer que o sistema de ensino municipal atende, em sua capacidade máxima, 60\% da demanda vigente. Isso demonstra que a maioria das DDZ estão sobrecarregadas, e algumas inclusive estão funcionando abaixo dessa média, como é o caso da DDZ Centro-Sul e DDZ Rural, o que compromete consideravelmente esse atendimento.

Tabela 3 - Capacidade de atendimento de salas de recursos multifuncionais por divisão distrital zonal (DDZ) - SEMED/MANAUS/2016.

\begin{tabular}{lccc}
\hline \multicolumn{1}{c}{$\begin{array}{c}\text { DISTRITO/DIVISÃO } \\
\text { DISTRITAL (DDZ) }\end{array}$} & $\begin{array}{c}\text { Matrículas } \\
\text { (Incluídos) }\end{array}$ & $\begin{array}{c}\text { SRM/SEMED } \\
\text { (Real) }\end{array}$ & $\begin{array}{c}\text { SRM/Pesquisa } \\
\text { (Ideal)(*) }\end{array}$ \\
\hline DRE VII (DDZ Rural) & 80 & 1 & 2,00 \\
DRE IV Norte (DDZ Centro-Sul) & 435 & 3 & 10,88 \\
DRE I Sul (DDZ Sul) & 431 & 6 & 10,78 \\
DRE VI (DDZ Leste II) & 433 & 7 & 10,83 \\
DRE III/Norte (DDZ Norte) & 525 & 7 & 13,13 \\
DRE V Leste I (DDZ Leste I) & 521 & 9 & 13,03 \\
DRE II Oeste (DDZ Oeste) & 599 & 13 & 14,98 \\
\multicolumn{1}{c}{ TOTAL } & $\mathbf{3 . 0 2 4}$ & $\mathbf{4 6}$ & $\mathbf{7 5 , 6 0}$ \\
\hline
\end{tabular}

Fonte: Inep/DEED/Censo Escolar. Elaboração própria.

Legenda: Divisão Regional de Ensino

$\left.{ }^{*}\right)$ Considerou-se, para efeito de cálculo, que 1 SRM atende 40 alunos por semana em sua capacidade máxima.

A partir disto, compreende-se que tão somente a inserção de alunos com necessidades educacionais especiais nas classes regulares, por si só, não garante uma prática inclusiva de ensino, pois se entende que também é importante investigar como estấo se dando as relaçóes nesse contexto, e até mesmo de questionar se existe diferença na relação entre professor e aluno, quando o aluno apresenta ou não uma deficiência, se as características dessas relaçóes afetam o processo de ensino e de aprendizagem, considerando a relaçáo entre o professor e o aluno como uma importante via de mediação da construção do conhecimento (SANTOS, 2014, p. 47-48).

\section{CONCLusóes}

Sendo assim, com base nos dados apresentados, e apesar da compreensão de que o AEE pode ser conduzido de forma individual ou em pequenos grupos conforme as necessidades educacionais específicas (MANAUS, 2016), a pesquisa revelou que o número de SRM 
não acompanhou o aumento do número de matrículas da Educação Especial no ensino regular, o que representa atualmente um déficit de $40 \%$ para atender esse público.

Por todos os fatores elencados, destaca-se a importância do AEE, principalmente nas escolas municipais, para os alunos do público-alvo da Educação Especial; e a redistribuição das SRM nas DDZ da rede municipal de ensino.

Constatou-se que apesar dos esforços da Secretaria de Educação Municipal em atender as necessidades desse público com relação ao AEE, o número de SRM ainda é insuficiente para suprir a demanda vigente, o que exige replanejamento das açôes estratégicas e a implantação de novas SRM.

Nessa direção, entende-se que tão somente inserir o aluno com necessidades educacionais especiais em classes comuns, não garante uma prática inclusiva de ensino, é importante investigar a qualidade do atendimento prestado e as características das relaçóes que ocorre no interior da escola e em seu entorno.

\section{REFERÊNCIAS}

ALVES, D.O. Sala de recursos multifuncionais: espaços para atendimento educacional especializado. Brasília: MEC/SEESP, 2006.

BERTUOL, C.L. Salas de recursos e salas de recursos multifuncionais: apoios especializados à inclusão escolar de alunos com deficiência/necessidades educacionais especiais no município de Cascavel-PR. 2010. 59f. Monografia (Pós-Graduação "Lato Sensu”) - Universidade Estadual do Oeste do Paraná, UNIOESTE, Paraná, 2010.

BRASIL. Constituição da República Federativa do Brasil. Brasília, DF: Senado, 1988.

BRASIL. MEC. Lei de diretrizes e bases da educação nacional: Lei n. 9.394/96. Brasília, DF: MEC, 1996.

BRASIL. MEC. Portaria Ministerial no 13/2007, de 24 de abril de 2007. Dispóe sobre a criação do "Programa de Implantação de Salas de Recursos Multifuncionais”. Brasília, DF: MEC, 2007.

BRASIL. MEC. Política nacional de educação especial na perspectiva da educação inclusiva. Brasília, DF: MEC, 2008.

BRASIL. MEC. Resolução no 4/2009, de 2 de outubro de 2009. Brasília, DF: Edições Câmara, 2009.

BRASIL. MEC. Decreto no 7611, de 17 de novembro de 2011. Brasília, DF: MEC, 2011.

BRASIL. MEC. Lei no 13.005, de 25 de junho de 2014. Aprova o Plano Nacional de Educação (PNE) e dá outras providências. Diário Oficial da União da República Federativa do Brasil, Brasília, DF:

MEC, 2014.

BRASIL. Lei brasileira de inclusão da pessoa com deficiência: Lei no 13.146, de 6 de julho de 2015. Brasília, DF: Câmara dos Deputados, Ediçôes Câmara, 2015.

BRASIL. INEP. Sinopse estatística da educação básica (2009 - 2015). Brasília, DF: INEP, 2016. Disponível em: <http://portal.inep.gov.br/basica-censo-escolar-sinopse-sinopse>. Acesso em: 28 nov. 2016.

FÁVERO, E. A. G.; PANTOJA, L. M. P.; MANTOAN, M. T. E. Atendimento educacional especializado: aspectos legais e orientaçôes pedagógicas. São Paulo: MEC/SEESP, 2007. 
GIL, A. C. Como elaborar projetos de pesquisa. 4. ed. São Paulo: Atlas, 2002.

KASPER, A.A. et al. Alunos com deficiência matriculados em escolas públicas de nível fundamental: algumas consideraçóes. Revista Educar, Curitiba, n.31, p.231-243, 2008.

MACHADO, R. Educação especial na escola inclusiva: políticas, paradigmas e práticas. São Paulo: Cortez, 2009.

MANAUS. Resolução no 011/CME/2016. Aprovada em 02.06.2016. Institui novos procedimentos e orientaçóes para Educação Especial na Perspectiva da Educaçáo Inclusiva, no Sistema Municipal de Ensino de Manaus. Diário Oficial do Município de Manaus. Ano XVII. Edição 2939.

NORONHA, G.C. Da forma à ação inclusiva: curso de formação de professores para atuar em salas de recursos multifuncionais. Jundiaí: Paco Editorial, 2016.

OLIVEIRA, R.M.G. Inclusão escolar: articulação entre sala de ensino regular e atendimento educacional especializado no município de Imperatriz, MA. In: COSTA, V.A. (Org.). Formação e pesquisa: articulação na educação inclusiva. Niterói: Intertexto, 2015.

SANTOS, L.M. A inclusão da criança com autismo na educação infantil: possibilidades de práticas pedagógicas. 2014. 129f. Dissertação (Mestrado em Educação) - Centro Universitário Moura Lacerda, Ribeirão Preto, 2014.

Recebido em: 06/06/2017

Reformulado em: 01/09/2017

Aprovado em: 13/09/2017 
SANTOS, J.O.L. et al. 